\title{
DEVELOPMENT OF SEMI-SYNTHETIC, REGIOSELECTIVE PATHWAYS FOR ACCESSING THE MISSING SULFATION PATTERNS OF CHONDROITIN SULFATE
}

\section{Supporting Information}

\author{
Giulia Vessella, ${ }^{1}$ Serena Traboni, ${ }^{1}$ Donatella Cimini, ${ }^{2}$ Alfonso Iadonisi, ${ }^{1}$ \\ ChIARA SCHIRALdi, ${ }^{2}$ EMILIANO BEDINI, ${ }^{1}$ \\ ${ }^{1}$ Department of Chemical Sciences, University of Naples Federico II, \\ Complesso Universitario Monte S.Angelo, via Cintia 4, I-80126 Napoli, Italy \\ ${ }^{2}$ Department of Experimental Medicine, Section of Biotechnology, \\ University of Campania "Luigi Vanvitelli”, via de Crecchio 7, I-80138 Napoli, Italy
}




\section{Table of Contents}

Table S1: ${ }^{1} \mathrm{H}$ and ${ }^{13} \mathrm{C}$ NMR chemical shift attribution of polysaccharides 4 and $5 \quad$ S-3

Table S2: ${ }^{1} \mathrm{H}$ and ${ }^{13} \mathrm{C}$ chemical shift attribution of structurally homogeneous CS-vi-viii S-3

Figure S1: ${ }^{1} \mathrm{H}$ and HSQC-DEPT NMR spectra of CS-i $\quad$ S-4

Figure S2: ${ }^{1} \mathrm{H}$ and HSQC-DEPT NMR spectra of CS-ii $\quad$ S-5

Figure S3: ${ }^{1} \mathrm{H}$ and HSQC-DEPT NMR spectra of CS-iii $\quad$ S-6

Figure S4: ${ }^{1} \mathrm{H}$ and HSQC-DEPT NMR spectra of CS-iv $\quad$ S-7

Figure S5: ${ }^{1} \mathrm{H}$ and HSQC-DEPT NMR spectra of CS-v $\quad$ S-8

Figure S6: ${ }^{1} \mathrm{H}$ and HSQC-DEPT NMR spectra of CS-vi $\quad$ S-9

Figure S7: ${ }^{1} \mathrm{H}$ and HSQC-DEPT NMR spectra of $4 \quad$ S-10

Figure S8: ${ }^{1} \mathrm{H}$ and HSQC-DEPT NMR spectra of $5 \quad$ S-11

Figure S9: ${ }^{1} \mathrm{H}, \mathrm{HSQC}-\mathrm{DEPT}$ and HMBC NMR spectra of 5 (zoom) S-12

Figure S10: ${ }^{1} \mathrm{H}$ and HSQC-DEPT NMR spectra of CS-vii $\quad$ S-13

Figure S11: ${ }^{1} \mathrm{H}$ and HSQC-DEPT NMR spectra of CS-viii $\quad$ S-14 
Table S1: ${ }^{1} \mathrm{H}$ (plain) and ${ }^{13} \mathrm{C}$ NMR (italic) chemical shift attribution of polysaccharides $\mathbf{4}$ and $\mathbf{5}^{[\mathrm{a}, \mathrm{b}]}$

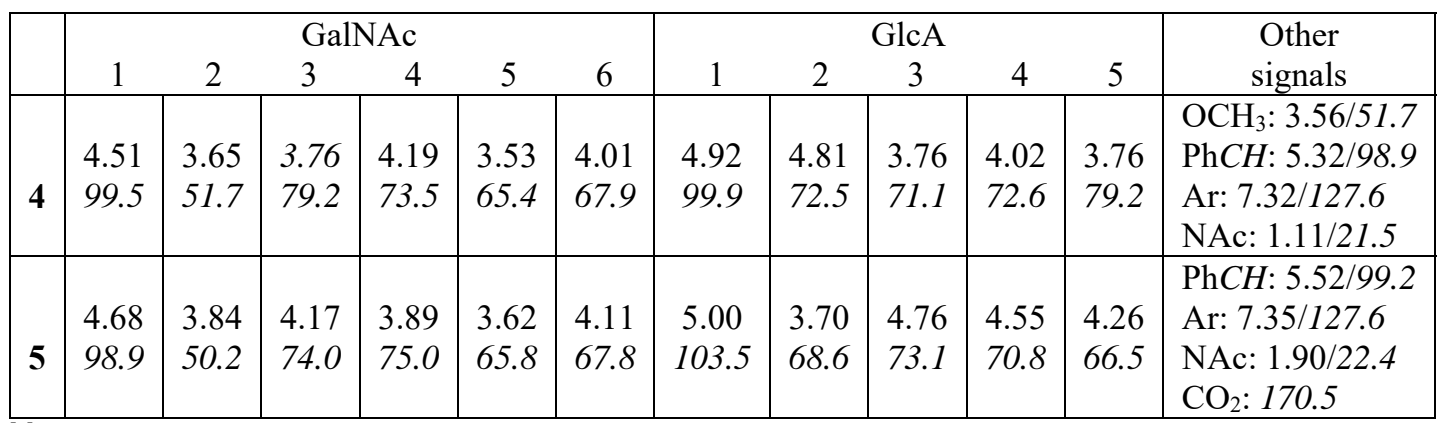

[a] NMR experiments conducted in DMSO-d 6 (600 MHz, $298 \mathrm{~K})$.

[b] Chemical shifts expressed in $\delta$ relative to isotopic impurity of DMSO- $d_{6}\left({ }^{1} \mathrm{H}: \mathrm{CHD}_{2} \mathrm{SOCD}_{3}\right.$ at $\delta=2.49 \mathrm{ppm})$ in DMSO- $d_{6}\left({ }^{13} \mathrm{C}: \mathrm{CD}_{3} \mathrm{SOCD}_{3}\right.$ at $\left.\delta=39.5 \mathrm{ppm}\right)$.

Table S2: ${ }^{1} \mathrm{H}$ (plain) and ${ }^{13} \mathrm{C}$ NMR (italic) chemical shift attribution of structurally homogeneous $\mathbf{C S}$-vi-viii ${ }^{[\mathrm{a}, \mathrm{b}]}$

\begin{tabular}{|c|c|c|c|c|c|c|c|c|c|c|c|c|}
\hline & \multicolumn{6}{|c|}{ GalNAc } & \multicolumn{5}{|c|}{ GlcA } & \multirow{2}{*}{$\begin{array}{c}\text { Other } \\
\text { signals }\end{array}$} \\
\hline & 1 & 2 & 3 & 4 & 5 & 6 & 1 & 2 & 3 & 4 & 5 & \\
\hline \multirow[t]{2}{*}{ CS-vi } & 4.65 & 4.06 & 3.88 & 4.19 & 3.66 & $3.90,3.70$ & 5.04 & 4.47 & 5.12 & 4.56 & 4.48 & \multirow{2}{*}{$\begin{array}{r}\text { NAc: } 2.08 \\
23.7\end{array}$} \\
\hline & 104.7 & 52.2 & 82.0 & 68.5 & 76.6 & 62.4 & 102.4 & 78.3 & 77.0 & 79.0 & 77.0 & \\
\hline \multirow[t]{2}{*}{ CS-vii } & 4.53 & 3.99 & 3.79 & 4.09 & 3.63 & $3.85,3.70$ & 4.59 & 3.59 & 4.37 & 3.98 & 3.70 & \multirow{2}{*}{$\begin{array}{r}\text { NAc: } 2.01 \\
23.8\end{array}$} \\
\hline & 102.2 & 52.1 & 81.8 & 68.8 & 75.8 & 62.0 & 104.8 & 73.3 & 82.5 & 78.9 & 76.1 & \\
\hline \multirow[t]{2}{*}{ CS-viii } & 4.54 & 3.92 & 3.91 & 4.15 & 3.68 & 3.77 & 4.72 & 4.10 & 3.81 & 3.86 & 3.72 & \multirow{2}{*}{$\begin{array}{r}\text { NAc: } 2.03 \\
23.8\end{array}$} \\
\hline & 101.8 & 51.9 & 80.9 & 68.4 & 75.2 & 62.1 & 102.5 & 80.6 & 73.9 & 80.0 & 77.2 & \\
\hline
\end{tabular}

${ }^{[a]}$ NMR experiments conducted in $\mathrm{D}_{2} \mathrm{O}(600 \mathrm{MHz}, 298 \mathrm{~K})$.

[b] Chemical shifts expressed in $\delta$ relative to internal acetone $\left({ }^{1} \mathrm{H}\right.$ : $\left(\mathrm{CH}_{3}\right)_{2} \mathrm{CO}$ at $\delta=2.22 \mathrm{ppm} ;{ }^{13} \mathrm{C}$ : $\left(\mathrm{CH}_{3}\right)_{2} \mathrm{CO}$ at $\left.\delta=30.9 \mathrm{ppm}\right)$. 


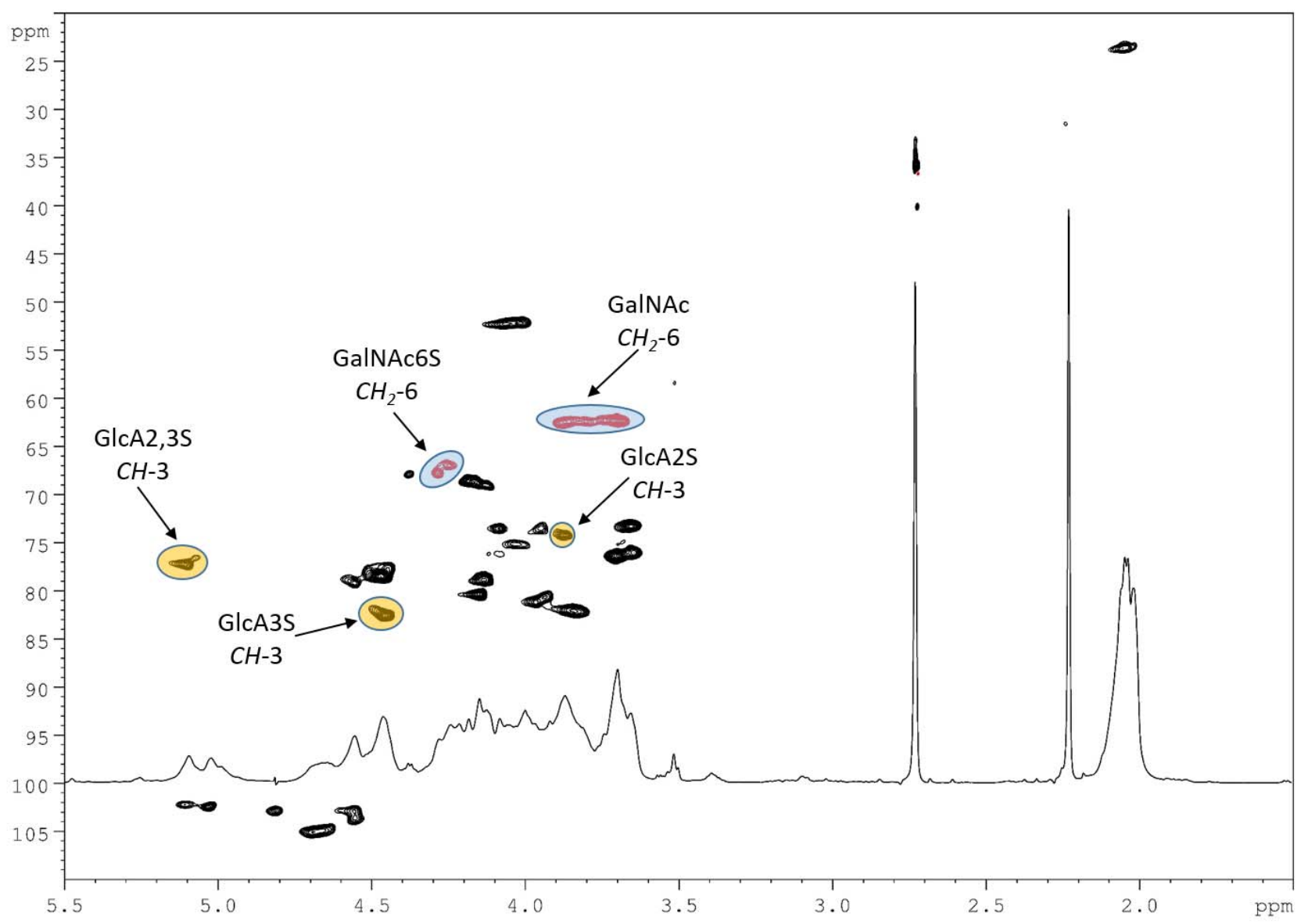

Figure S1: ${ }^{1} \mathrm{H}$ and HSQC-DEPT NMR spectra (600 MHz, $\mathrm{D}_{2} \mathrm{O}, 298 \mathrm{~K}$ ) of CS-i

(densities enclosed in the highlighted areas were integrated for GlcA2,3S-GlcA3S-GlcA2S and GalNAc-GalNAc6S ratios estimation) 


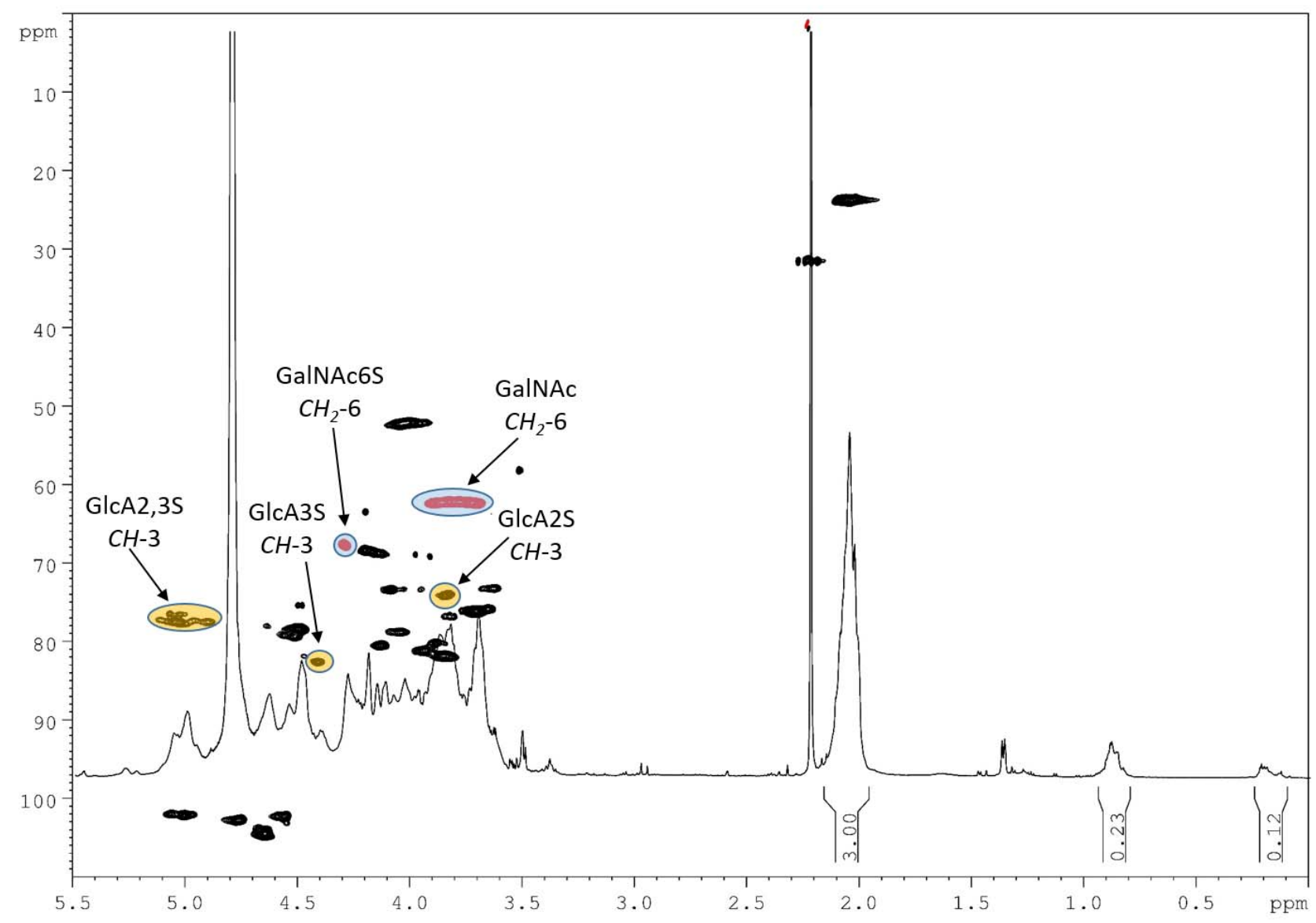

Figure S2: ${ }^{1} \mathrm{H}$ and HSQC-DEPT NMR spectra (600 MHz, $\left.\mathrm{D}_{2} \mathrm{O}, 298 \mathrm{~K}\right)$ of $\mathbf{C S}-\mathrm{ii}$

(densities enclosed in the highlighted areas were integrated for GlcA2,3S-GlcA3S-GlcA2S and GalNAc-GalNAc6S ratios estimation) 


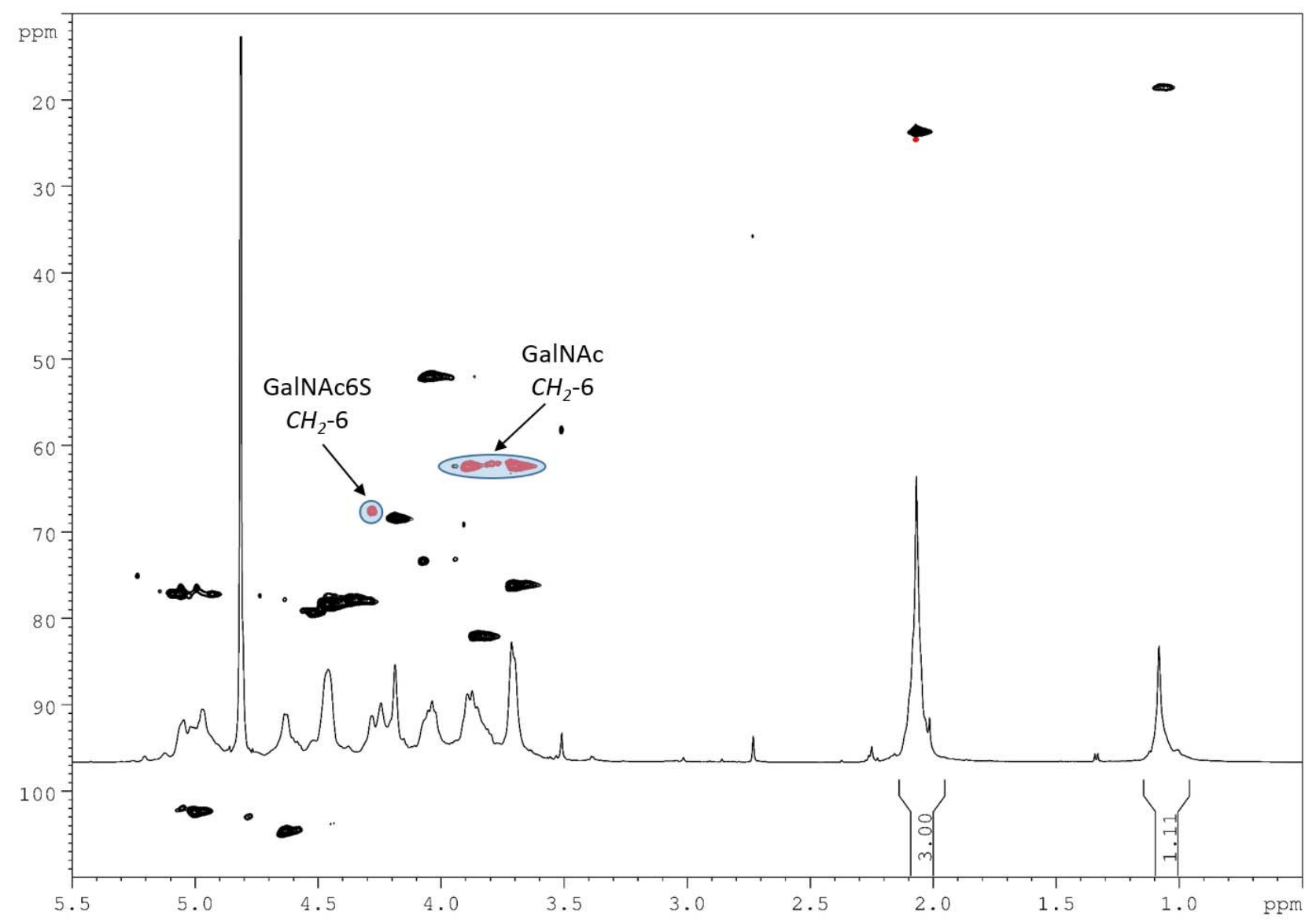

Figure S3: ${ }^{1} \mathrm{H}$ and HSQC-DEPT NMR spectra (600 MHz, $\mathrm{D}_{2} \mathrm{O}, 298 \mathrm{~K}$ ) of CS-iii (densities enclosed in the highlighted areas were integrated for GalNAc-GalNAc6S ratio estimation) 


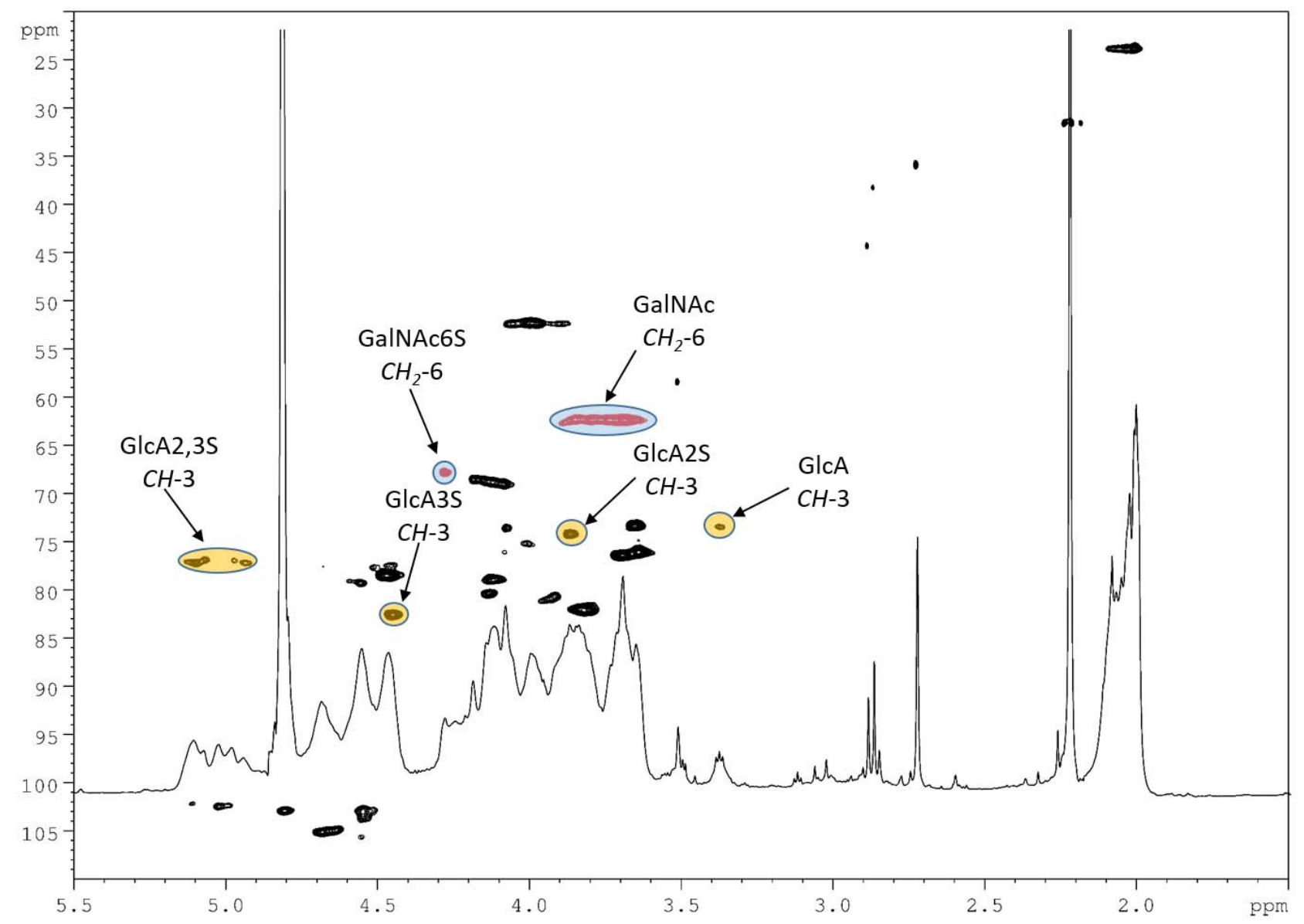

Figure S4: ${ }^{1} \mathrm{H}$ and HSQC-DEPT NMR spectra (600 MHz, $\mathrm{D}_{2} \mathrm{O}, 298 \mathrm{~K}$ ) of CS-iv

(densities enclosed in the highlighted areas were integrated for GlcA2,3S-GlcA3S-GlcA2S and GalNAc-GalNAc6S ratios estimation) 


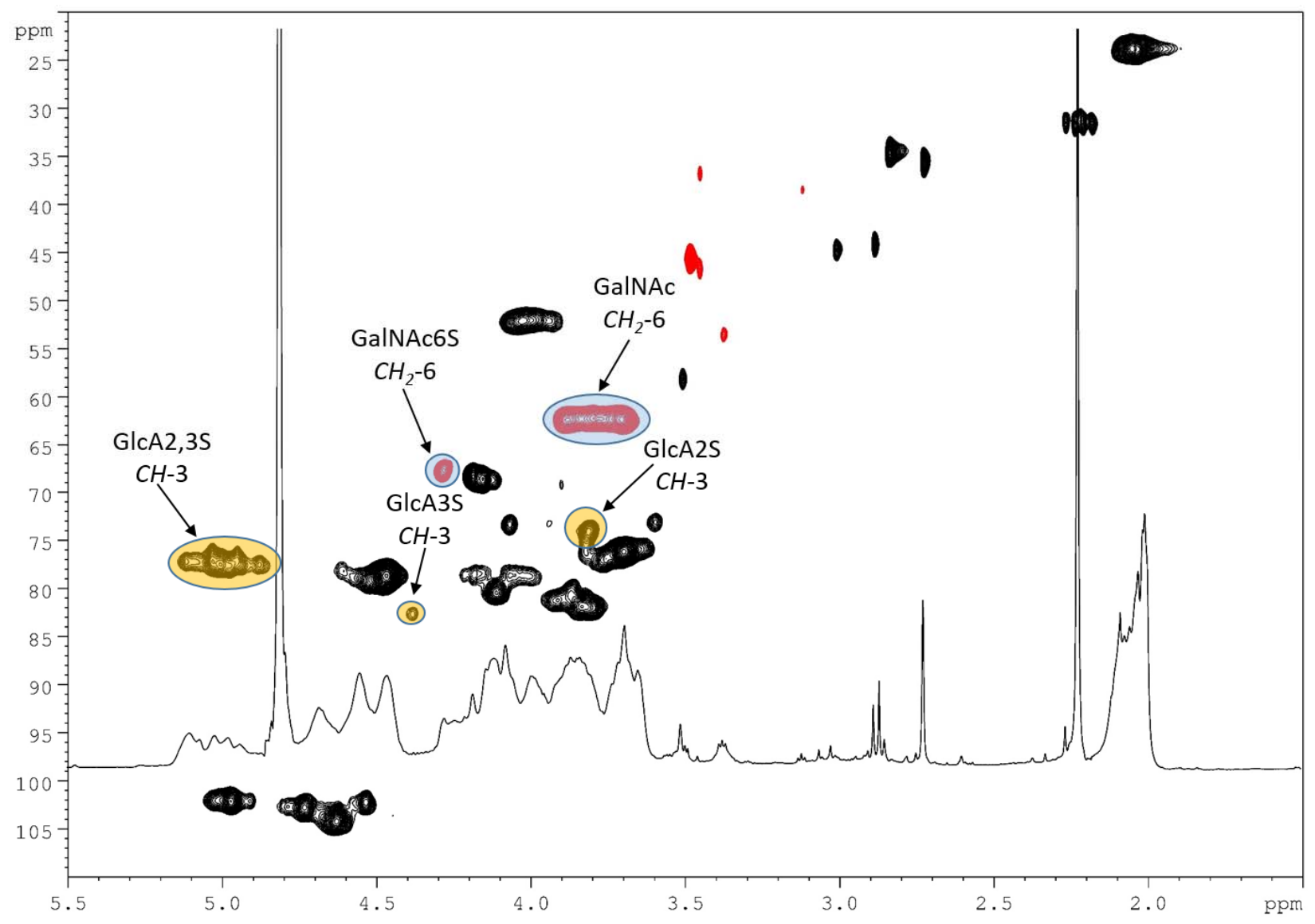

Figure S5: ${ }^{1} \mathrm{H}$ and HSQC-DEPT NMR spectra (600 MHz, $\left.\mathrm{D}_{2} \mathrm{O}, 298 \mathrm{~K}\right)$ of $\mathbf{C S - v}$

(densities enclosed in the highlighted areas were integrated for GlcA2,3S-GlcA3S-GlcA2S and GalNAc-GalNAc6S ratios estimation) 


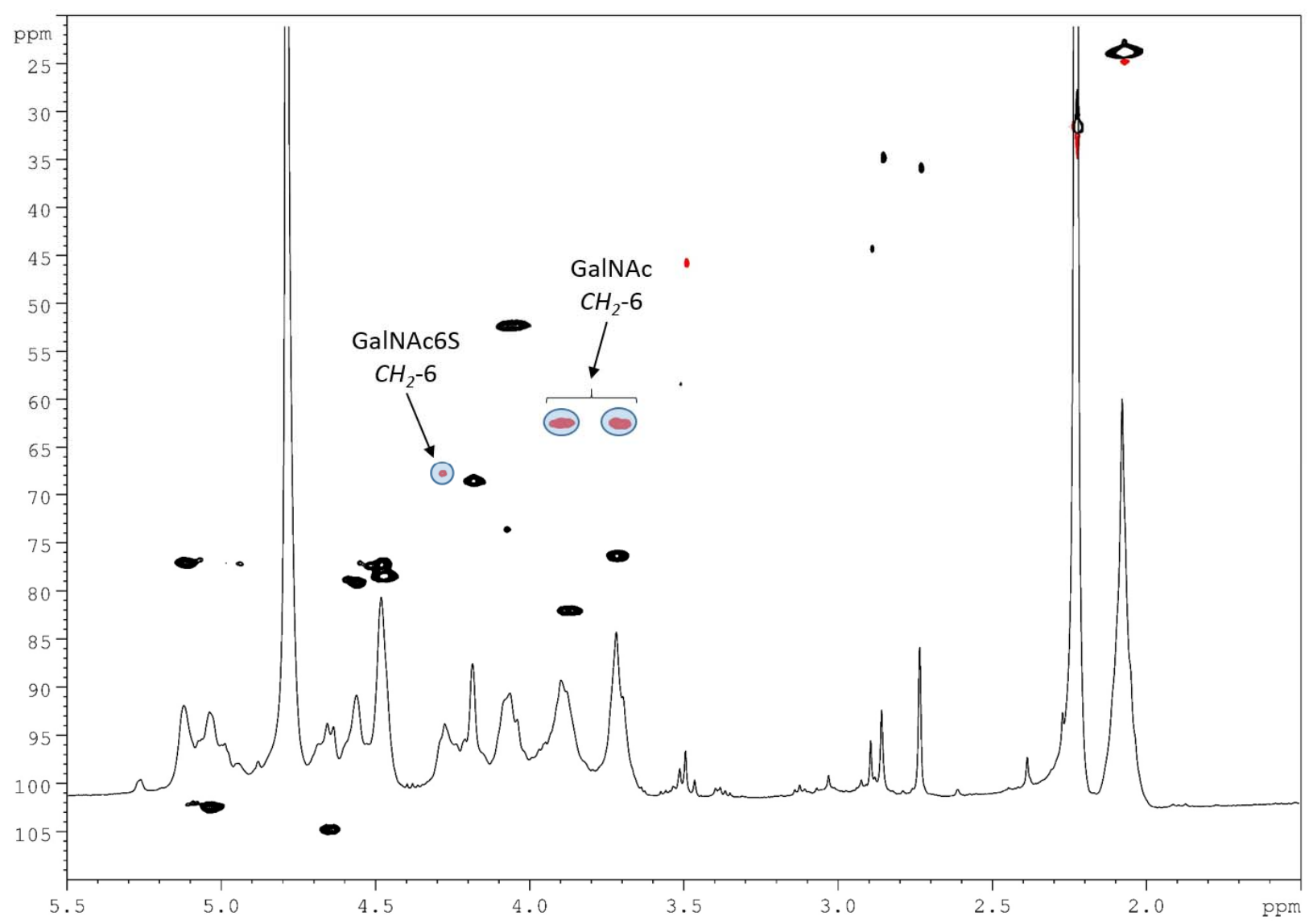

Figure S6: ${ }^{1} \mathrm{H}$ and HSQC-DEPT NMR spectra (600 MHz, $\left.\mathrm{D}_{2} \mathrm{O}, 298 \mathrm{~K}\right)$ of CS-vi

(densities enclosed in the highlighted areas were integrated for GalNAc-GalNAc6S ratio estimation) 


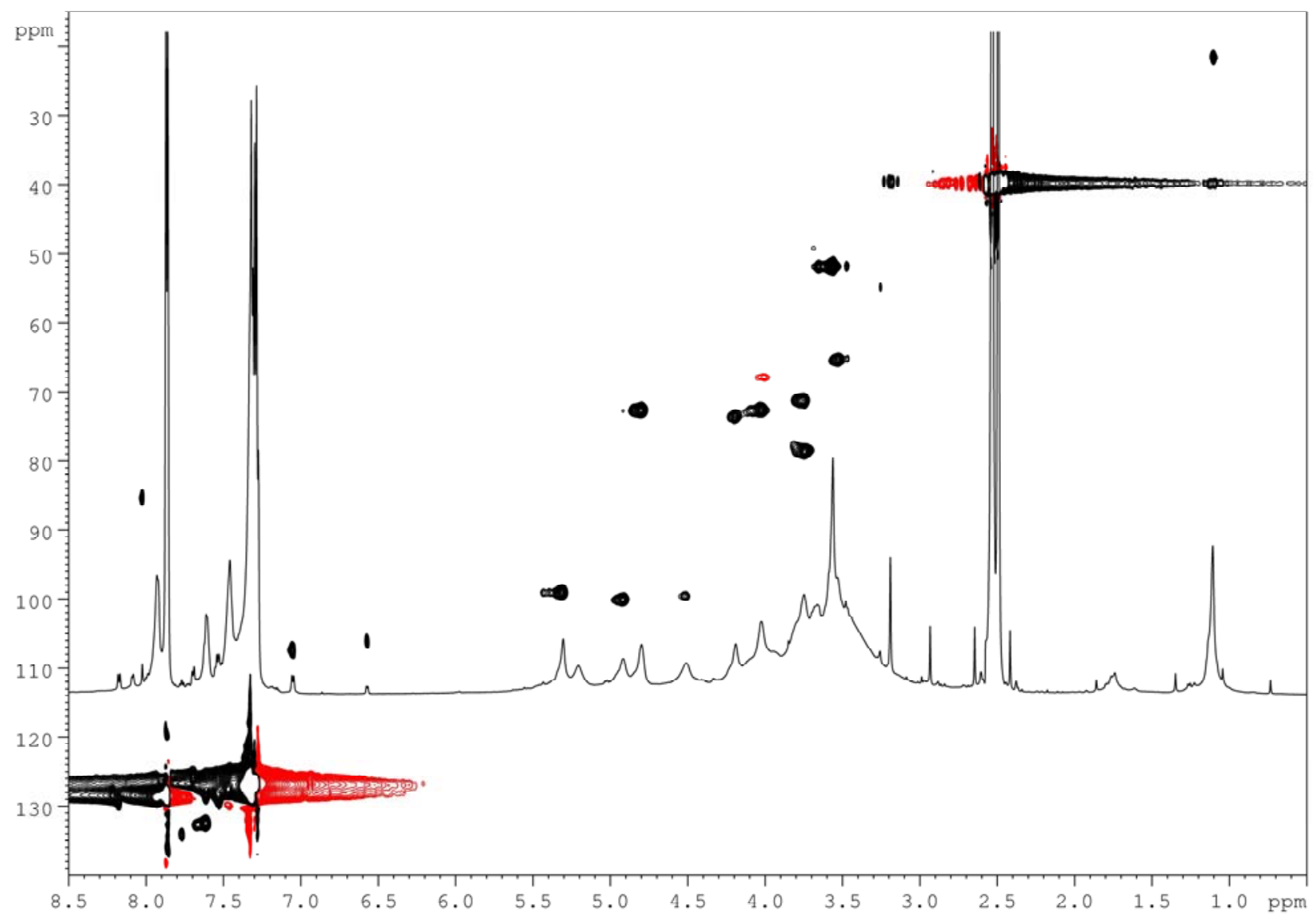

Figure S7: ${ }^{1} \mathrm{H}$ and HSQC-DEPT NMR spectra $\left(600 \mathrm{MHz}\right.$, DMSO- $\left.d_{6}, 298 \mathrm{~K}\right)$ of 4 


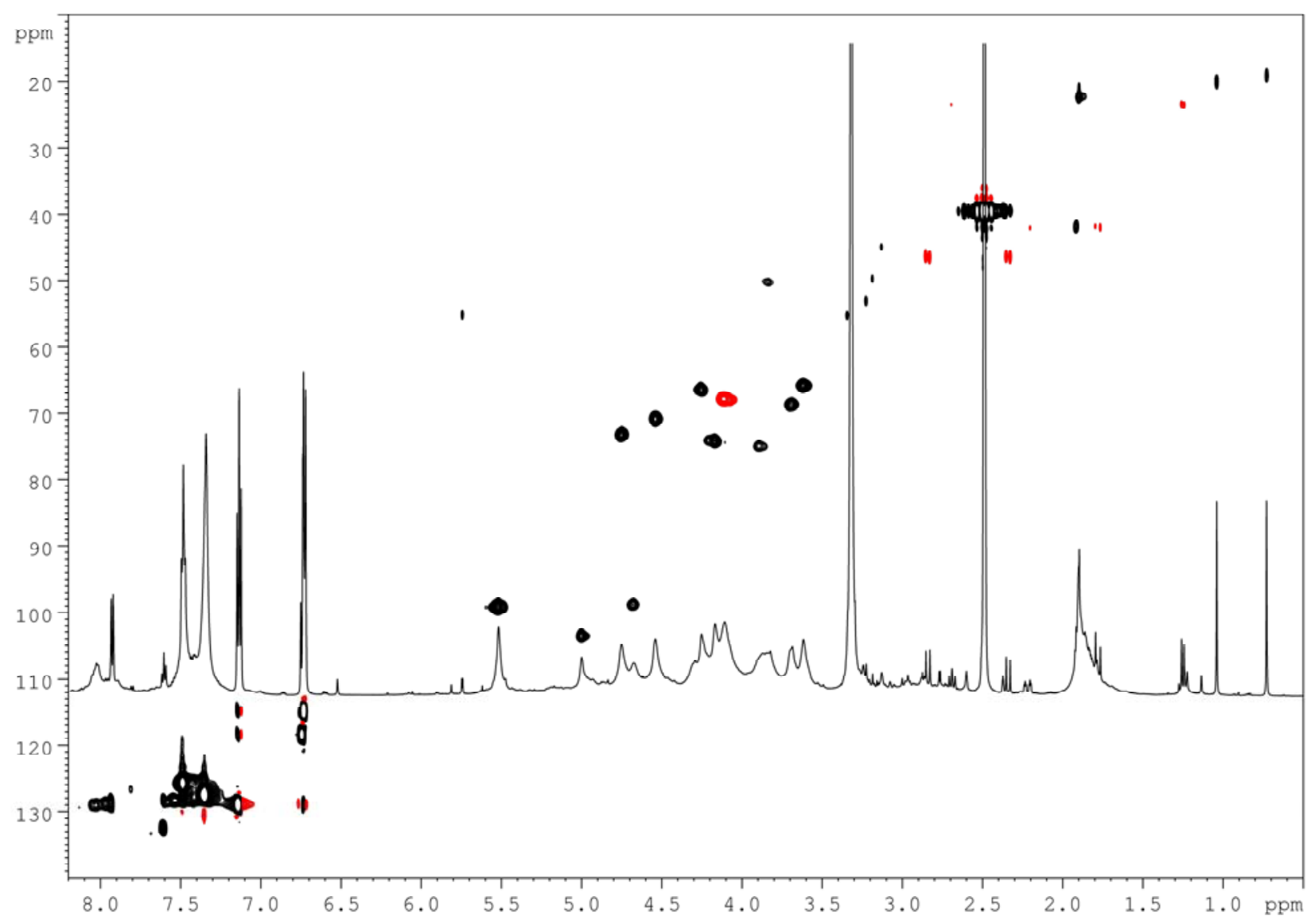

Figure S8: ${ }^{1} \mathrm{H}$ and HSQC-DEPT NMR spectra (600 MHz, DMSO-d $d_{6}, 298 \mathrm{~K}$ ) of 5 


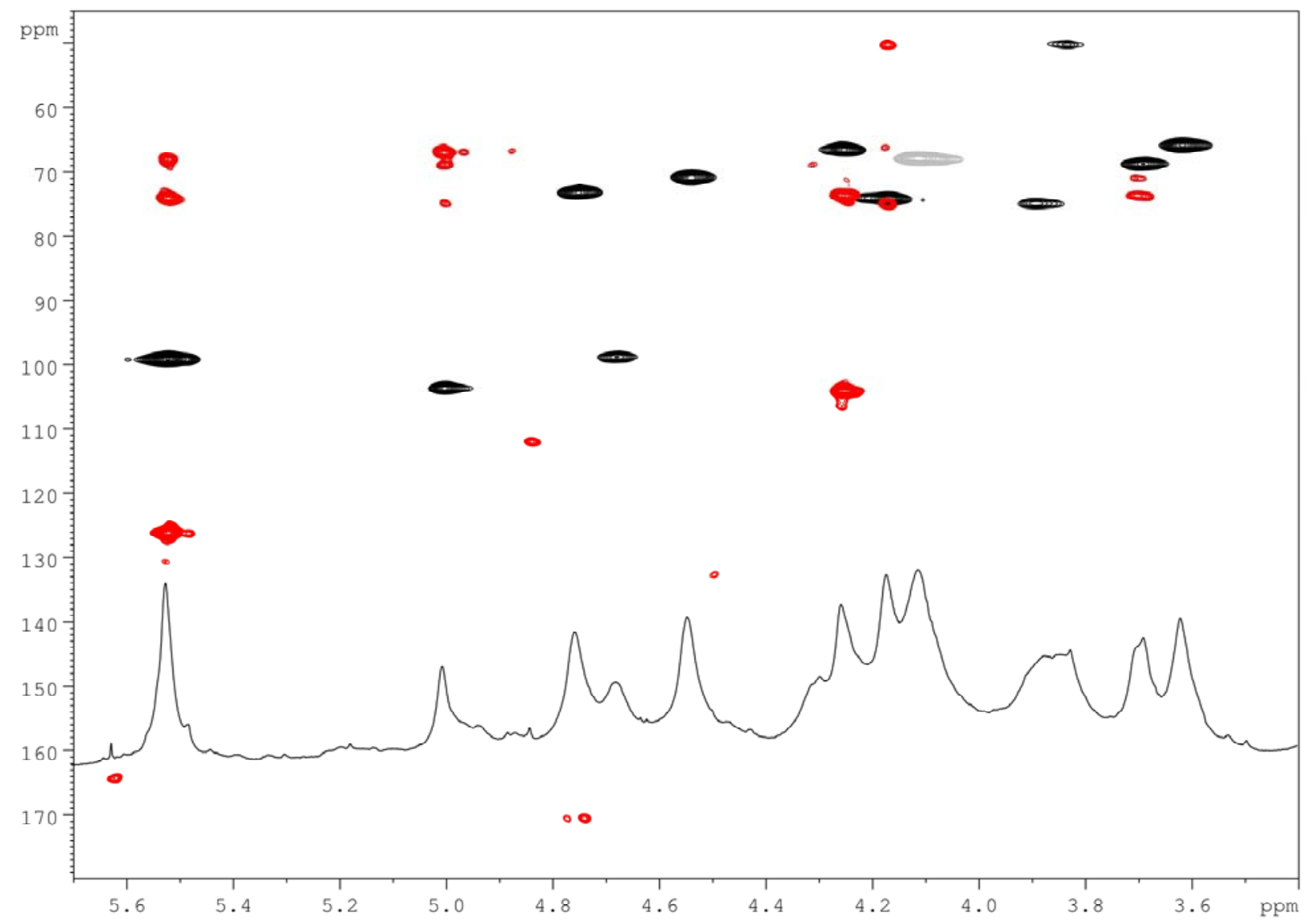

Figure S9: ${ }^{1} \mathrm{H}, \mathrm{HSQC}-\mathrm{DEPT}$ (black and grey) and HMBC (red) NMR spectra (zoom, $600 \mathrm{MHz}$, DMSO-d $\mathrm{d}_{6}, 298 \mathrm{~K}$ ) of 5 


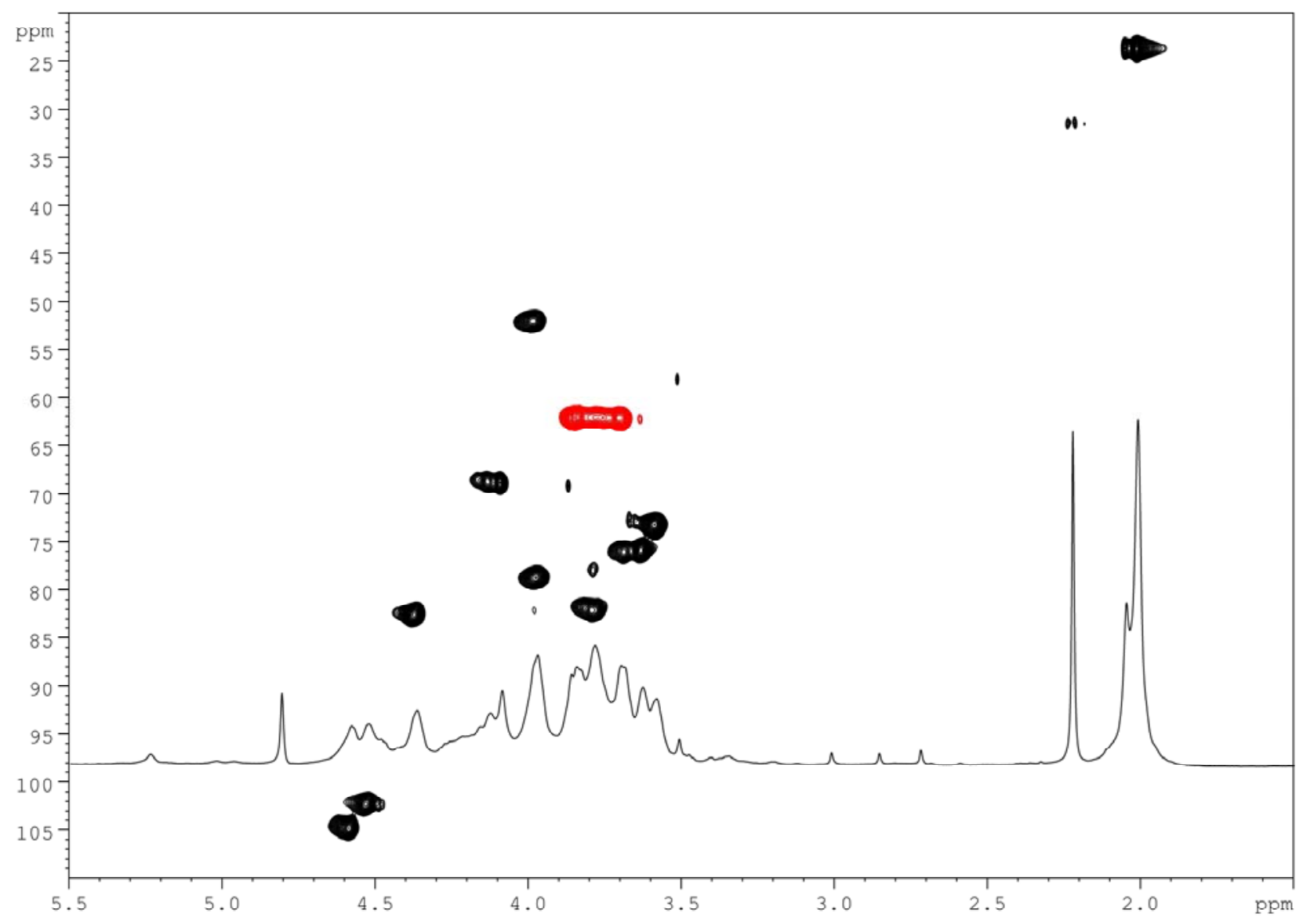

Figure S10: ${ }^{1} \mathrm{H}$ and HSQC-DEPT NMR spectra (600 MHz, $\left.\mathrm{D}_{2} \mathrm{O}, 298 \mathrm{~K}\right)$ of CS-vii 


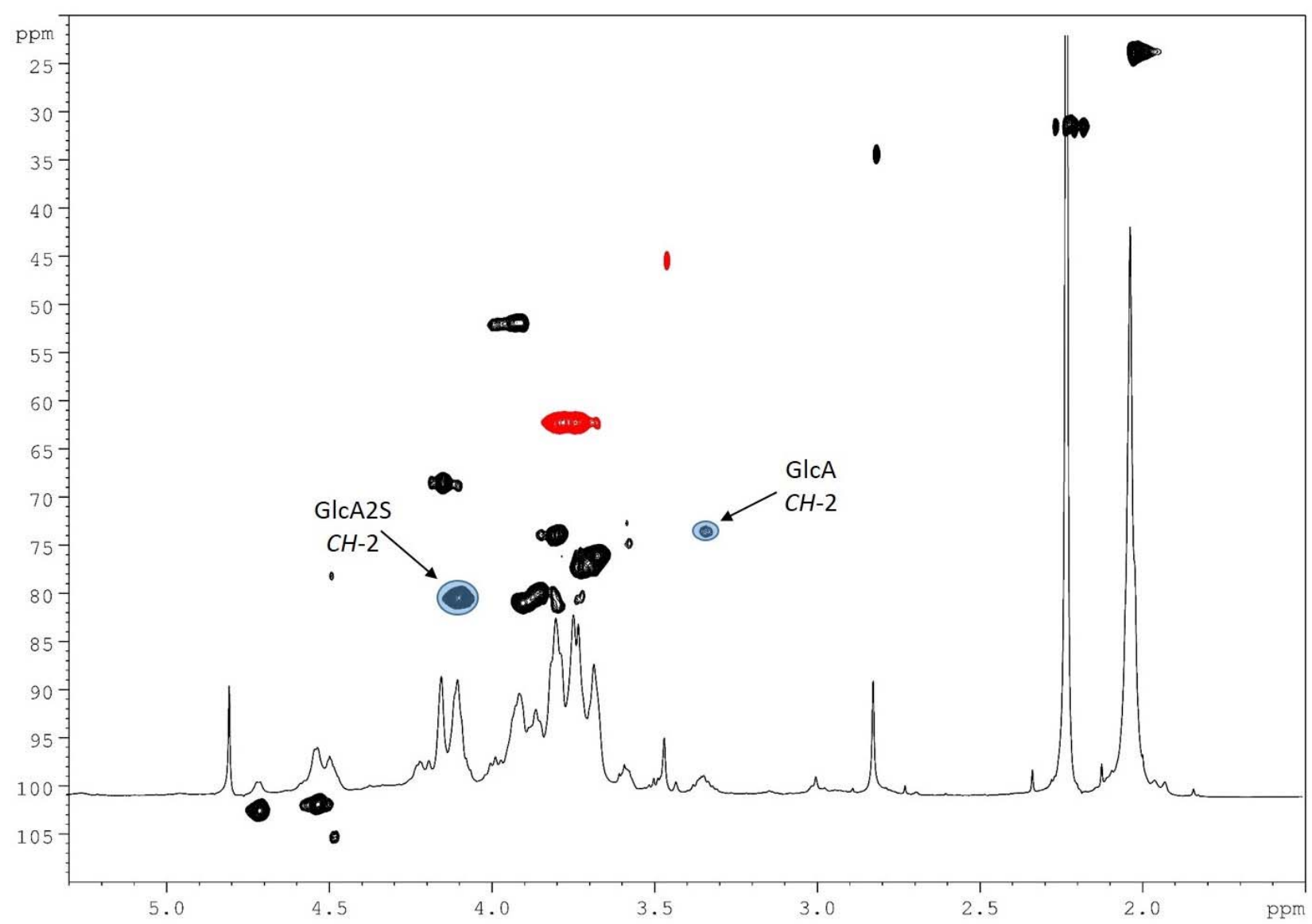

Figure S11: ${ }^{1} \mathrm{H}$ and HSQC-DEPT NMR spectra (600 MHz, $\mathrm{D}_{2} \mathrm{O}, 298 \mathrm{~K}$ ) of CS-viii

(densities enclosed in the highlighted areas were integrated for estimation of GlcA2S and GlcA percentage amounts) 